\title{
Neuromarketing: Marketing research in the new millennium
}

\author{
Ahmed H. Alsharif *, Nor Zafir Md Salleh and Rohaizat Baharun
}

Azman Hashim International Business School, Universiti Teknologi Malaysia, 81310 Skudai, Johor, Malaysia.

* Correspondence: ahmedalsharif07@gmail.com; Tel.: +601161271610

Received: 24 June 2021; Accepted: 20 August 2021; Published: 14 September 2021

Edited by: Aida Azlina Mansor (Universiti Teknologi MARA, Malaysia)

Reviewed by: Salmi Mohd Isa (Universiti Sains Malaysia, Malaysia);

Chiemelie Benneth Iloka (Enugu State University of Science and Technology, Nigeria)

https://doi.org/10.31117/neuroscirn.v4i3.79

\begin{abstract}
Neuromarketing (NM) uses neuroscience tools, for example, but not limited to functional magnetic resonance imaging (fMRI) and electroencephalography (EEG) to study, explore, analyze, and explain the neural correlates of consumer's behavior (i.e., decision-making processes), the cognitive processes (i.e., attention and memory) and emotional processes (i.e., emotion) of interest for marketing research (e.g., advertising, brand, product, price). This study analyzes the relevant literature and sheds light on the triune brain of humans, the dimensions of NM such as emotion, attention, and memory. Currently, emotional and cognitive processes have remarkably received attention from academic and industrial environments. Thus, NM presents unrivalled possibilities to record the activity regions in consumers' brains and provide precise information about which neurons are active when consumers are exposed to marketing stimuli. To best our knowledge, this will aid in shaping and understanding the central theme and set the future research directions for the researchers.
\end{abstract}

Keywords: neuromarketing; triune brain; neuromarketing tools; emotion; attention; memory;

C2021 by Alsharif et al. for use and distribution according to the Creative Commons Attribution (CC BY-NC 4.0) license (https://creativecommons.org/licenses/by-nc/4.0/), which permits unrestricted non-commercial use, distribution, and reproduction in any medium, provided the original author and source are credited.

\subsection{INTRODUCTION}

Traditional marketing studies were followed self-report methods (e.g., questionnaires, interviews) for a long time to assess, understand, predict, and analyze the consumer's behavior consciously toward marketing stimuli such as advertisements (Carrington et al., 2014). On the other side, the unconscious behavior of consumers is largely not measured by traditional methods. Therefore, traditional marketing methods are not effective in measuring unconscious processes such as emotions, attention, and memory, which drive the majority of decision-making processes in the human brain (Plassmann et al., 2012). Accordingly, it is now widely accepted that the unconscious and subconscious mind is more important than the conscious mind in marketing practices and advertising researches (Anuar et al., 2021; Vecchiato et al., 2013). Therefore, the limitations of traditional marketing methods to measure consumers' behavior accurately have led researchers and marketers to adopt new methods named "neuromarketing" (Alsharif et al., 2021e). NM is highly important for the academic and industrial environment to overcome the limitations in traditional methods such as consumer social bias (e.g., self-report of consumers can be affected by others choices), besides, individuals say something and do something else because they do not become aware of what they want by using neuroscience methods such as functional magnetic resonance imaging (fMRI) and electroencephalography (EEG) (Fortunato et al., 2014). Therefore, NM will change the face of marketing by moving marketing research from visible to invisible and from conscious to unconscious world without 
investigating individuals verbally (self-report) (Nemorin \& Gandy-Jr, 2017).

Therefore, to better strengthen the concept behind the actual consumer behavior, we must understand the stimulating elements behind the actual behavior, which lies in the consumer's brain 'black box'. For that to take place we need to dig a little deeper inside the consumer's brain to understand the basics of 'neuromarketing', which involves a set of definitions, NM is an interdisciplinary field, situated at the borderline between neuroscience, psychology, and marketing (Alsharif et al., 2021b; Javor et al., 2013; Sebastian, 2014), it uses to create a better structure of how marketing stimuli (e.g., advertising, brand, product) impact the neural responses of consumer's behavior (e.g., decision-making), emotion, attention, and memory processes (Pozharliev et al., 2017). NM is mainly associated with the commercial part that correlates to the application of neuroscience tools in marketing research to give a well-oriented image on the consumption behavior as a whole (Khushaba et al., 2013). Delving deeper into that sense, the NM gives us a closer look into the hidden side of reality rather than the traditional market research (Agarwal \& Dutta, 2015).

\subsection{Neuromarketing}

Researchers, advertisers, and marketers have sought a long time to explore what is inside consumers' brains and what are they thinking of to determine the subtle centers in the brain, which lead them to make decisions (Alsharif et al., 2020). NM has emerged according to a hyper-competitive environment among companies (Plassmann et al., 2012). Ale Smidt was the first to coin the term 'Neuromarketing' in $\mathbf{2 0 0 2}$ who defined it as the study of the brain's mechanisms for understanding consumers' behavior to optimize marketing strategies (Orzan et al., 2012). The last decade has been a huge glowing era for NM science as an emerging concept that can significantly affect market research, it gives impactful insights about the decision-making processes and the unconscious responses (e.g., emotions, attention, and memory) of the consumer toward marketing stimuli (Ramos et al., 2017). The first study in NM was done in 2003 by McClure et al. (2004), published in 2004. This experiment investigated the neural correlates of the brain responses toward two types of soda drinks (e.g., Coca-Cola and Pepsi Cola). Their findings showed that in the blind test of drinks, stronger activation in the orbitofrontal cortex, which is related to enjoy something, but in brand logo test the researchers noticed that a stronger activation in hippocampus and dorsolateral prefrontal cortex with Coca-Cola brand which are associated with memory, emotion, and affect, but with Pepsi Cola no such activation was found. This experiment was considered as the first study which convey NM from pure study to practical study. Consequently, it has become an indisputable academic field to integrate data from neuroscience and functional neuroimaging (Mileti et al., 2016; Ramos et al., 2017).

Marketing research has evolved from studying the consciousness of consumers' behavior to studying the unconscious of consumers' responses toward products, brands, and advertisements (Stanton et al., 2017). The purpose of NM is to study the consumer behavior (i.e., decision-making process), the cognitive (i.e., attention and memory), and emotional (i.e., emotion) processes toward marketing stimuli (Alsharif et al., 2020). Consequently, NM has contributed to marketing development by explaining how unconscious responses (e.g., emotion, memory, and attention) can affect consumers' decision-making processes (Mileti et al., 2016). The NM provides more precise information to answer the marketing questions about the unconscious consumer's behavior toward brands, advertisings, and decision-making processes which is impossible by traditional marketing methods (Kenning \& Linzmajer, 2011).

NM has derived from three main fields, namely, neuroscience, psychology, and marketing (Page, 2012; Sebastian, 2014). Therefore, marketing research defines NM as the application of neuroscience, including the use of advanced medical techniques, to solve the marketing issue. According to the literature, NM uses neuroimaging and physiological tools to clearly understand consumers' thoughts with the potential of identifying the 'buy buttons' in consumers' brains to develop marketing research and create more effective marketing strategies (Alsharif et al., 2021e). This review will provide the basic information about NM and the brain processes of interest for marketing research; thereby, this is valuable for new researchers in the NM domain to improve their ideas and thoughts.

This study provides valuable information about brain components and functions (e.g., neocortex, limbic, and reptilian brain). Additionally, brain processes such as emotion, attention, and memory are crucial to understanding better what drives consumers' behavior. Therefore, this study will be beneficial for new researchers in the NM domain to understand the basic processes and functions of the brain. Different from 
review papers related to $\mathrm{NM}$, in terms, this study discusses the NM techniques and throws light on the human brain neuroanatomy, such as the neocortex brain, limbic brain, and reptilian brain. The main objectives of this study are to provide an overview of the current NM, alongside shed light on the dimensions of NM such as emotion, attention, and memory. For the high-quality study, we tried to deeply investigate as many articles as possible on the relevant topics. When we talk about NM and consumer neuroscience, we should speak of NM tools. In the following section, NM tools will be discussed briefly.

This article is organized as follows. Section 2 presents an overview of the NM tools. Section 3 presents the triune brain. Section 4 provides valuable information about NM dimensions (e.g., emotion, memory, and attention). Section 5 share the ethical issues of NM. Finally, Section 6 concludes the work.

\subsection{NEUROMARKETING TOOLS}

For decades, marketing research has relied on traditional marketing methods such as surveys, focus groups, and interviews for data collection (Jordao et al., 2017). However, changing market structures (e.g., offline to online) need new methods and tools that can adapt to a hyper-competitive marketing environment. Thus, both environment academic and industrial fields have investigated how marketing research can benefit from integrating these tools and methods to develop marketing research (Plassmann et al., 2012). Because traditional marketing methods are overtly measuring conscious reports of consumers' experiences and thoughts. On the other side, the unconscious and subconscious of consumers' reactions are largely unmeasured by traditional methods. NM tools have the potential to understand, explore, analyze, and explain unconscious drivers of choice (Alsharif et al., 2021e). These days, researchers and scholars are highly interested in exploring what is in the consumers' brains and what they are thinking of by employing NM tools (Alsharif et al., 2020). NM tools have been classified into four main groups: i) neuroimaging tools such as functional magnetic resonance imaging ( $\mathrm{fMRI}$ ), positron emission tomography (PET), electroencephalography (EEG), magnetoencephalography (MEG), functional near-infrared spectroscopy (fNIRS), single-photon emission tomography (SPET), and steady-state topography (SST), (ii) physiological tools such as electrocardiogram (ECG), eye-tracking (ET), facial electromyography (fEMG), galvanic skin response (GSR), (iii) self-report such as surveys, interviews, focus groups, and (iv) behavioral measurements such as implicit association test (IAT) (Ramsoy, 2015). Figure 1 presents the current classifications of the NM tools.

Neuroimaging tools measure the activity in the main brain processes and functions such as emotion, attention, and memory toward marketing stimuli such as brand, product, services, ads (Alsharif et al., 2021d; Lim, 2018). Physiological tools can capture the physiological functions such as heartbeat, sweating, eye movements, blood pressure, facial muscle movements during consumers' exposure to marketing stimuli and at purchase point, thereby, they provide valuable information about consumer behavior such as pleasure/displeasure. Moreover, neuroimaging and physiological tools allow scholars to explore, analyze, and predict buying behavior such as engagement, excitement, approach/withdrawal behavior (Alsharif et al., 2021e; Cherubino et al., 2019). Behavioral measurements offer important information about the behavior of consumers such as like/dislike, impression, recognition, and concerns. Self-report is one of the most widely employed methods for data collection about consumer status, including beliefs and attitudes (Ramsoy, 2015). These methods have been considered as the four main pillars of NM applications. The fMRI and EEG are the most favorite methods for scientists and researchers to measure the consumer's brain responses toward marketing stimuli such as advertisings (Alsharif et al., 2021e). NM tools are associated with measuring the consumers' brains' responses; thereby, in the following section, we will talk about the different structures and functions of the brain, which is crucial to understand what drives consumer behavior.

\subsection{TRIUNE BRAIN}

Although the human brain represents only $2 \%$ of the body weight, it consumes approximately $20 \%$ of the body's energy. This leads to infer that the brain is the key to most consumer choices. MacLean \& George (1990) suggested a brilliant model of the human brain structure which has three main components, namely, the neocortex (rational) brain, limbic (emotional) brain, and reptilian (primitive) brain (Dragolea \& Cotirlea, 2011). When we talk about NM, we should talk about different brain structures because these structures play a significant role in better understanding what drives consumer behavior. In the following section, it will be discussed the taxonomy of the human brain briefly.

\subsection{Neocortex brain}

The neocortex is the largest part of the mammal's brain that covers approximately the whole brain except the cerebellum and accounts for approximately $76 \%$ of the 


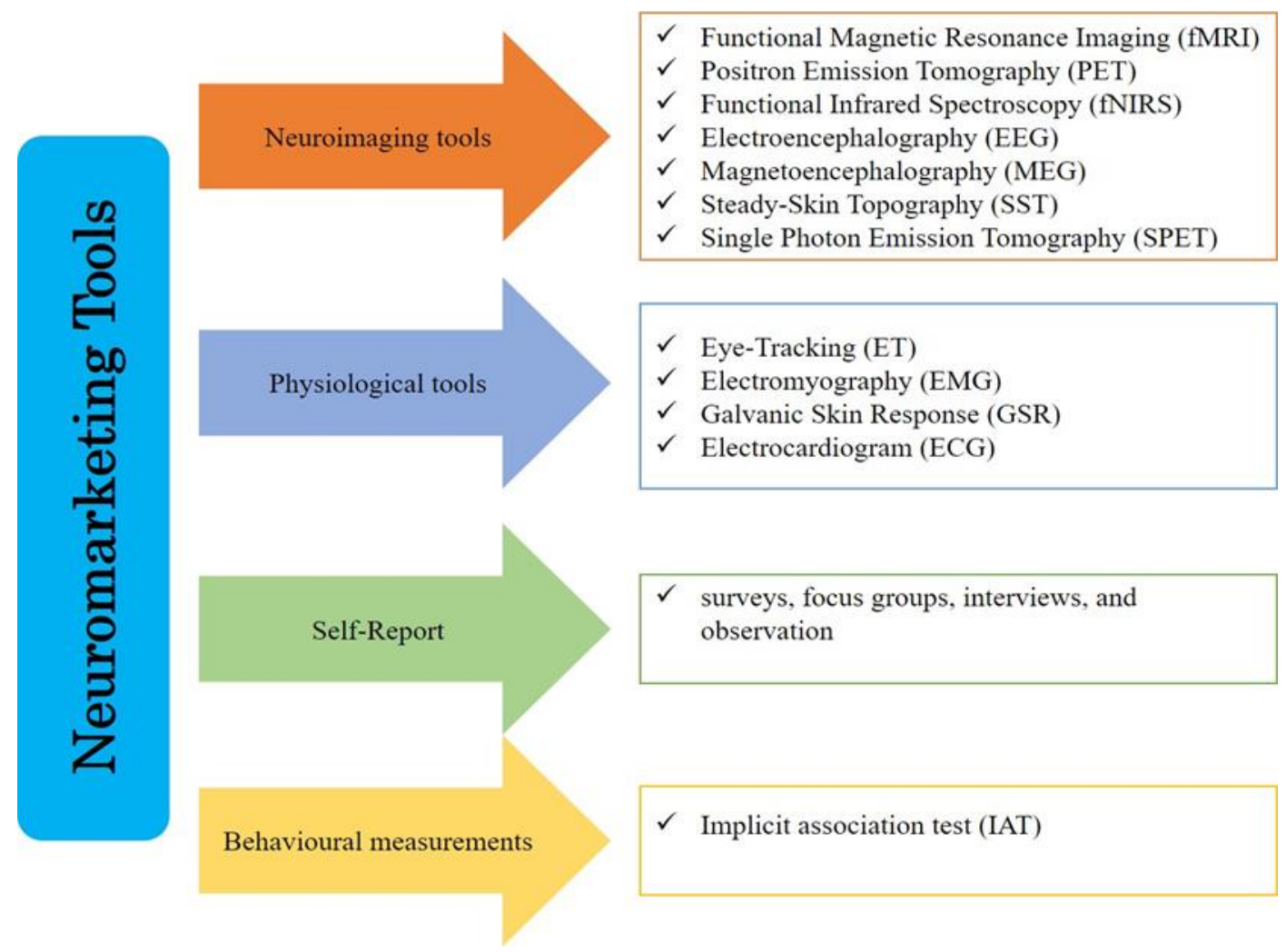

Figure 1: The classifications of neuromarketing tools.

human brain volume. The neocortex is also extensively wrinkled, making the brain much efficient due to the increase of the surface area of the brain and neurons. The cerebral cortex is divided into two symmetrical halves (e.g., right and left) with slightly different functions, known as hemispheres (Spielman et al., 2014). The right hemisphere of the brain controls the left part of the body, wherein the right hemisphere is also engaged in non-verbal information (e.g., recognition of faces, music, visual imaging), in addition, emotional expressions and communication with others. Meanwhile, the right part of the body is controlled by the left part of the brain (i.e., left hemisphere), responsible for logic and analysis, languages. But the functions of the hemispheres is still not fully understanding as right-brain related with creative and left-brain linked to logic (Kalat, 2015). This part of the brain engages in several functions, such as sensory perception, cognition, motor command generation (Lodato \& Arlotta, 2015), language and spatial reasoning (Lui et al., 2011). The neocortex is divided into four lobes: the frontal, parietal, temporal, and occipital lobes.

\subsection{Limbic brain}

Broca was the first one to coin the term 'limbic system'. This system is located underneath the cerebral cortex to form a circle around the brainstem, later known as the 'limbic lobe' (Catani et al., 2013; Chow et al., 2018). In the beginning, the limbic system was considered the nervous system, which controls and organizes emotion but is now regarded as only a part of the brain. After that, several studies discovered that people's emotions are associated with this layer in the brain (Chow et al., 2018; Papez, 1937). Nearly all outgoing signals from the senses are transferred by the thalamus and the signals from other subcortical areas; in addition, several areas in the neocortex are communicating through the thalamus. The limbic system includes the hypothalamus, hippocampus, amygdala, thalamus, and cingulate cortex (Chow et al., 2018).

\subsection{Reptilian brain}

The reptilian brain consists of the cerebellum directly connected with the spinal cord and sometimes referred to as the reptilian complex or the 'lizard brain' because all living creatures have basic functions that must be performed to sustain life (e.g., breathing, temperature). Although this part of the brain is small, it holds much more neurons than other parts of the brain. Vertebrates have a cerebellum, which is considered the oldest part of the brain (Hodos, 2009). The cerebellum is responsible for maintaining equilibrium and posture, motor learning, and accurate timing. Therefore, an 
individual with damage in this part is suffering from equilibrium disorders, posture, and motor learning (Fine et al., 2002). The spinal cord, along with the brain, makes up the central nervous system (CNS). The function of the spinal cord is to transfer nerve signals from the motor cortex to the whole body and from the afferent nerve fibers of the sensory neurons to the sensory cortex aside from organizing many reflexes. It controls the body's vital functions (e.g. circulation, body temperature, balance, breathing, and so forth) and the human conduct when it is working as a quick decisionmaker, such as but not limited to, what strategy must be taken very quickly as wait, withdrawal, defense or any visual stimuli when exposed to threats (Sirico Jr, 2017).

As we noticed in the brain layers, all these layers are working together to accomplish tasks of consumers' behavior such as emotional and cognitive processes to continue their lives; therefore, we will discuss the emotion, attention, and memory processes as the significant dimensions of NM in the next section.

\subsection{NEUROMARKETING DIMENSIONS}

The fMRI investigation of Zaltman $(\underline{2000})$ revealed that the majority of consumer behavior (e.g., decisionmaking) occurs in the deep mind unconsciously or subconsciously (Ruschendorf, 2020). According to Genco et al. (2013), emotion, attention, and memory are the three dimensions that neuromarketers and scholars are interested in measuring. For example, NM research concentrate on how consumers evaluate, process, and experience marketing stimuli (Morillo et al., 2016).

\subsection{Emotion}

Emotion is essential to consumers' behaviors, wherein consumers cannot evaluate their options without it (Scheff et al., 1995). Emotion is considered the unconscious emotional reactions such as approaching, avoidance, and valence, which play a crucial role in the consumers' decision-making processes at the purchase point (Alsharif et al., 2021a). Feelings are considered as the result of conscious emotional status, which is derived from individuals' assessment of an event (e.g., level of pleasure or unpleasure) (Scherer, 2005). Therefore, emotion and feeling can be used by scholars to grab the consumer's attention and impact his behavior, wherein positive emotion (i.e., pleasant) can lead a consumer to approach behavior while negative emotion (e.g., unpleasant) lead to withdrawal/avoidance behavior (Alsharif et al., 2021c).
It can be distinguished between emotion and feeling through the physiological (i.e., sweating, increase heartbeat) versus psychological (i.e., feeling of being pleasure or fear) aspects, respectively (LeDoux \& Brown, 2017). Although there are several emotion theories such as Evolutionary theory, James-Lange, Cannon-Bard, and so forth. The concept of emotion has been described based on the following theory by scholars. For example, several neuroscience studies have defined emotion as the set changes of the somatic and brain status as a result of the human responses based on the perceptions of humans (Damasio, 2003). Frijda (1987) defined emotion as the tendency of humans to create, maintain, or terminate a relationship with the environment or with others. These definitions are still hotly debated (Barrett, 2012; Dixon, 2012). For example, basic emotions include fear, anger, disgust, happiness, sadness, and so on (Stewart et al., 2018). Lazarus (2006) pointed out that emotion corresponds with a construct that consumers create, and due to that the basic emotional reactions are constant for everyone. Finally, the majority of scholars are agreed on the two dimensions for measuring emotions: Arousal and valence (Knutson et al., 2007; Russell \& Barrett, 1999). Valence refers to the positive or negative response of consumers toward marketing stimuli such as brand, product, ads, whereas, arousal refers to the intensity of emotional responses (i.e., high or low arousal) (Figure 2) (Alsharif et al., 2021c; Cherubino et al., 2019).

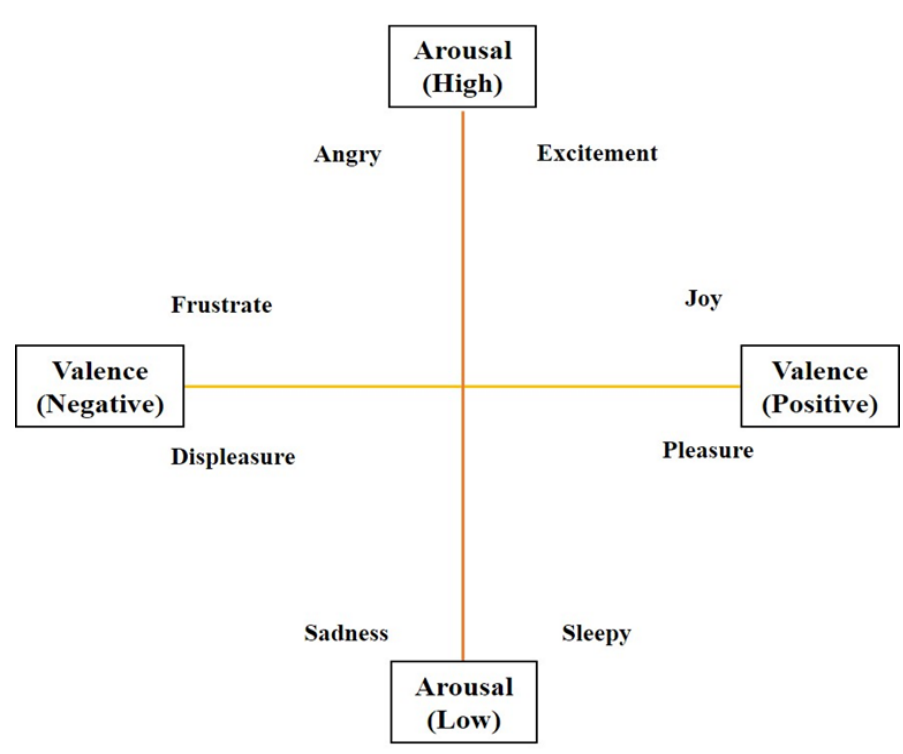

Figure 2: Valence and arousal model of emotions. This figure is reproduced without any modifications from Alsharif et al. (2021e) under the open access terms and creative common license CC BY 4.0 . 


\subsection{Attention}

Attention is defined as the attraction of the consumers' minds to one purpose among many purposes simultaneously. The focus is considered the essence of it and involves removing some ambiguity to deal with others effectively. According to Du Plessis (2005), attention sometimes works on a subconscious level. Paying attention to something means focusing on particular aspects and ignoring several others around, alongside attention is working as a filter, which leads consumers to focus on some prominent items in the products over the others. Emotion and attention are highly connected (Matthews \& Wells, 1999). Accordingly, the products or services associated with emotional responses have probability more attract to our attention to them (Genco et al., 2013). According to previous articles, there are two types of attention systems in the brain as top-down (voluntary) and bottom-up (Involuntary) (Milosavljevic et al., 2012). Bottom-up attention is an involuntary concentration by the external world (e.g., stimulus-driven allocation). On the other hand, voluntary attention is oriented attention based on internal needs (e.g., goal-driven allocation) (Schiller et al., 2009).

\subsection{Memory}

Memory is the most complicated dimension among the others. Memory has the functions of input and output in the brain, the input element is encoding/storing memories while the output element is the recovery of these memories. So, marketers attach high importance to both of them in memory because both have a conscious and unconscious part in the brain (Genco et al., 2013). Memory is defined as a learning process that continues over time, terms it could be retrieved information that has been stored (Myers \& DeWall, 2021). Therefore, we are gathering experience to use it during our lives, which enhance the significance of daily truths through learning and memory. As stated by (Du Plessis, 2005) the involuntary nature of emotions and memories are extremely strong psychological processes which out of our control. Memory and emotional processes work together toward marketing messages, brands, and products to form their reactions. According to Myers \& DeWall (2021), quoted Atkinson \& Shiffrin (1968) who presented the multistore model of memory and is a classic model, this model consisted of three stages: a sensory register, short-term memory, and long-term memory.

NM field is using neuroscience tools to study consumer's brain processes such as emotion, attention, and memory, which lead us to ethics. An ethical issue is one of the most sensitive in NM. Therefore, ethical issues will be discussed in the next section.

\subsection{ETHICAL ISSUES}

NM advancement has led to discuss the ethical issues related to the "buy button" in the consumers' minds (Isa et al., 2019). When the media reported that advertisers and marketers could use NM tools to analyze consumers' private thoughts, emotions, attention, and memory to influence their decision-making (Spence, 2020). Many researchers and scientists have emphasized that NM will threaten consumers' privacy if that technology accurately deals with consumer behavior (Murphy et al., 2008). In reality, the protection becomes more critical for children, people with neurological disease, and patients because they are weak, more sensitive, and easy to deceive them using NM techniques (Luna \& Macklin, 2013). For example, Chen et al. (2018) conducted an experiment by using $f M R I$ to examine the impact of e-cigarette ads campaigns on adolescents. The findings revealed that ecigarette ads had increased smoking desire. This lead to infer that it is easy to deceive and exploit adolescent by cigarette companies. A previous study showed that cigarettes ads enhance the desire for smoking and decision-making processes. Nevertheless, some claimed that such fears are potentially premature because stateof-the-art imaging technology does not accurately predict consumer choices (Brammer, 2004). Ethics have therefore been seen as the most important considerations to weigh in the conduct of NM work by neuroscientists and neuro-marketers. The ethical aspect is the biggest challenge facing NM technology application in marketing researches (UIman et al., 2015). In the following section, we will conclude our works, future directions, limitation, and recommendation for researchers.

\subsection{CONCLUSIONS}

NM is a promising field to solve the marketing issues by studying the unconscious processes in the consumers' minds because most decision-making processes have occurred unconsciously or subconsciously. Consequently, NM will change the face of marketing because it provides valuable information about decision-making processes, which are quite impossible to get by traditional marketing methods. In summary, NM research is highly significant for academic and industrial environments to overcome the biases in the traditional methods such as self-report. There is a limited amount of research that has strictly been listed and focuses on emotion, attention, and memory. From 
the authors' perspectives, this field needs new researchers to conduct their work/research on NM dimensions. For future directions, marketing research will understand consumers' behavior more effectively by using NM methods. NM will provide more valuable insights about neural correlates of consumers' behavior, emotional and cognitive processes toward marketing stimuli. Therefore, NM will reduce the self-report bias and increase the accuracy and reliability of marketing practices. Thus, scientists and researchers have to use NM to improve people's lives, not for their own goals. Besides, do not use NM methods to impact children by promoting harmful products such as fast foods, cigarettes.
Acknowledgments: The authors would like to thank Universiti Teknologi Malaysia (UTM), Azman Hashim International Business School (AHIBS) for supporting this study.

Author Contributions: AHA: Conceptualization and writing the original draft of the manuscript; NZMS and RB: Supervision, reviewing, and editing the draft. All authors have read and agreed to the published version of the manuscript.

Conflicts of Interest: The authors declare no conflict of interest.

\section{References}

Agarwal, S., \& Dutta, T. (2015). Neuromarketing and consumer neuroscience: Current understanding and the way forward. Decision, 42(4), 457-462. https://doi.org/10.1007/s40622-015-0113-1

Alsharif, A. H., Salleh, N. Z. M., \& Baharun, R. (2021a). The neural correlates of emotion in decision-making. International Journal of Academic Research in Business and Social Sciences, 11(7), 64-77. https://doi.org/10.6007/ijarbss/v11-i7/10075

Alsharif, A. H., Salleh, N. Z. M., \& Baharun, R. (2021b). Neuromarketing: The popularity of the brain-imaging and physiological tools. Neuroscience Research Notes, 3(5), 13-22. https://doi.org/10.31117/neuroscirn.v3i5.80

Alsharif, A. H., Salleh, N. Z. M., \& Baharun, R. (2021c). To better understand the role of emotional processes in decisionmaking. International Journal of Academic Research in Economics and Management Sciences, 10(2), 49-67. https://doi.org/10.6007/ijarems/v10-i2/9883

Alsharif, A. H., Salleh, N. Z. M., Baharun, R., \& Effandi, Y. M. (2021d). Consumer behaviour through neuromarketing approach. Journal of Contemporary Issues in Business and Government, 27(3), 344-354. https://doi.org/10.47750/cibg.2021.27.03.048

Alsharif, A. H., Salleh, N. Z. M., Baharun, R., Rami Hashem E., A., Mansor, A. A., Ali, J., \& Abbas, A. F. (2021e). Neuroimaging techniques in advertising research: Main applications, development, and brain regions and processes. Sustainability, 13(11), 6488-6513. https://doi.org/10.3390/su13116488

Alsharif, A. H., Salleh, N. Z. M., Baharun, R., \& Safaei, M. (2020). Neuromarketing approach: An overview and future research directions. Journal of Theoretical and Applied Information Technology, 98(7), 991-1001.

Anuar, N. N. A., Isa, S. M., \& Mansor, A. A. (2021). Subconscious response on marketing mix for green and non-green goods: $A$ neuromarketing study. National \& International Conference, Bangkok, Thailand. 1(12), 73-83.

Atkinson, R. C., \& Shiffrin, R. M. (1968). Human memory: A proposed system and its control processes. Psychology of Learning and Motivation, 2, 89-195. https://doi.org/10.1017/cbo9781316422250.025

Barrett, L. F. (2012). Emotions are real. Emotion, 12(3), 413. https://doi.org/10.1037/a0027555

Brammer, M. (2004). Brain scam? Nature Neuroscience, 7(10), 1015-1015. https://doi.org/10.1038/nn1004-1015

Carrington, M. J., Neville, B. A., \& Whitwell, G. J. (2014). Lost in translation: Exploring the ethical consumer intentionbehavior gap. Journal of Business Research, 67(1), 2759-2767. https://doi.org/10.1016/i.jbusres.2012.09.022

Catani, M., Dell'Acqua, F., \& De Schotten, M. T. (2013). A revised limbic system model for memory, emotion and behaviour. Neuroscience Biobehavioral Reviews, 37(8), 1724-1737. https://doi.org/10.1016/i.neubiorev.2013.07.001

Chen, Y., Fowler, C. H., Papa, V. B., Lepping, R. J., Brucks, M. G., Fox, A. T., \& Martin, L. E. (2018). Adolescents' behavioral and neural responses to e-cigarette advertising. Addiction Biology, 23(2), 761-771. https://doi.org/10.1111/adb.12510

Cherubino, P., Martinez-Levy, A. C., Caratu, M., Cartocci, G., Di Flumeri, G., Modica, E., . . Trettel, A. (2019). Consumer behaviour through the eyes of neurophysiological measures: State of the art and future trends. Computational Intelligence and Neuroscience, 3(2), 01-41. https://doi.org/10.1155/2019/1976847

Chow, Y., Masiak, J., Mikołajewska, E., Mikołajewski, D., Wójcik, G. M., Wallace, B., . . Olajossy, M. (2018). Limbic brain structures and burnout- A systematic review. Advances in Medical Sciences, 63(1), 192-198. https://doi.org/10.1016/i.advms.2017.11.004

Damasio, A. R. (2003). Looking for Spinoza: Joy, sorrow, and the feeling brain. Houghton Mifflin Harcourt. https://doi.org/10.1016/i.cub.2004.05.004

Dixon, T. (2012). Emotion: The history of a keyword in crisis. Emotion Review, 4(4), 338-344. https://doi.org/10.1177/1754073912445814 
Dragolea, L., \& Cotirlea, D. (2011). Neuromarketing: between influence and manipulation. Polish Journal of Management Studies, 3, 78-88.

Du Plessis, E. (2005). The advertised mind: Ground-breaking insights into how our brains respond to advertising. Kogan Page Publishers. https://doi.org/10.2501/s0021849906000158

Fine, E. J., lonita, C. C., \& Lohr, L. (2002). The history of the development of the cerebellar examination. Seminars in Neurology, 22(4): 375-384. https://doi.org/10.1055/s-2002-36759

Fortunato, V. C. R., Giraldi, J. D. M. E., \& Oliveira, J. H. C. D. (2014). A review of studies on neuromarketing: Practical results, techniques, contributions and limitations. Journal of Management Research, 6(2), 201-221. https://doi.org/10.5296/jmr.v6i2.5446

Frijda, N. H. (1987). Emotion, cognitive structure, and action tendency. Cognition and Emotion, 1(2), 115-143. https://doi.org/10.1080/02699938708408043

Genco, S., Pohlmann, A., \& Steidl, P. (2013). Neuromarketing for dummies. USA. John Wiley \& Sons.

Hodos, W. (2009). In E. a. t. s. naturae (Ed.), Evolution of cerebellum (pp. 1212-1219). MD, USA. Encyclopedia of Neuroscience. https://doi.org/10.1007/978-3-540-29678-2 3124

Isa, S. M., Mansor, A. A., \& Razali, K. (2019). Ethics in neuromarketing and its Implications on Business to Stay Vigilant. KnE Social Sciences, 2019, 687-711. https://doi.org/10.18502/kss.v3i22.5082

Javor, A., Koller, M., Lee, N., Chamberlain, L., \& Ransmayr, G. (2013). Neuromarketing and consumer neuroscience: Contributions to neurology. BMC Neurology, 13(1), 13. https://doi.org/10.1186/1471-2377-13-13

Jordao, I. L. D. S., Souza, M. T. D., Oliveira, J. H. C. D., \& Giraldi, J. D. M. E. (2017). Neuromarketing applied to consumer behaviour: An integrative literature review between 2010 and 2015. International Journal of Business Forecasting and Marketing Intelligence, 3(3), 270-288. https://doi.org/10.1504/ijbfmi.2017.10006047

Kalat, J. W. (2015). Biological psychology. Toronto, USA. Nelson Education.

Kenning, P., \& Linzmajer, M. (2011). Consumer neuroscience: an overview of an emerging discipline with implications for consumer policy. Journal of Consumer Protection and Food Safety, 6(1), 111-125. https://doi.org/10.1007/s00003-010$\underline{0652-5}$

Khushaba, R. N., Wise, C., Kodagoda, S., Louviere, J., Kahn, B. E., \& Townsend, C. (2013). Consumer neuroscience: Assessing the brain response to marketing stimuli using electroencephalogram (EEG) and eye tracking. Expert Systems with Applications, 40(9), 3803-3812. https://doi.org/10.1016/i.eswa.2012.12.095

Knutson, B., Rick, S., Wimmer, G. E., Prelec, D., \& Loewenstein, G. (2007). Neural predictors of purchases. Neuron, 53(1), 147156. https://doi.org/10.1016/i.neuron.2006.11.010

Lazarus, R. S. (2006). Stress and emotion: A new synthesis. London, UK. Springer Publishing Company. https://doi.org/10.1046/j.1365-2850.1999.00227-9.x

LeDoux, J. E., \& Brown, R. (2017). A higher-order theory of emotional consciousness. Proceedings of the National Academy of Sciences, 114(10), E2016-E2025. https://doi.org/10.1073/pnas.1619316114

Lim, W. M. (2018). Demystifying neuromarketing. Journal of Business Research, 91, 205-220. https://doi.org/10.1016/i.jbusres.2018.05.036

Lodato, S., \& Arlotta, P. (2015). Generating neuronal diversity in the mammalian cerebral cortex. Annual Review of Cell Developmental Biology, 31, 699-720. https://doi.org/10.1146/annurev-cellbio-100814-125353

Lui, J. H., Hansen, D. V., \& Kriegstein, A. R. (2011). Development and evolution of the human neocortex. Cells, 146(1), 18-36. https://doi.org/10.1016/j.cell.2011.06.030

Luna, F., \& Macklin, R. (2013). Research involving human beings, vulnerability and exploitation. In A companion to bioethics (2nd ed., pp. 459-468). West Susses, UK. John Wiley \& Sons. https://doi.org/10.1002/9781444307818.ch38

MacLean, P. D., \& George, M. S. (1990). The triune brain in evolution: Role in paleocerebral functions. Cognitive and Behavioral Neurology, 5(1), 68-84. https://doi.org/10.1126/science.250.4978.303-a

Matthews, G., \& Wells, A. (1999). The Cognitive Science of Attention and Emotion (Tim Dalgleish \& M. J. Power Eds.). John Wiley \& Sons, Ltd. https://doi.org/10.1002/0470013494.ch9

McClure, S. M., Li, J., Tomlin, D., Cypert, K. S., Montague, L. M., \& Montague, P. R. (2004). Neural correlates of behavioral preference for culturally familiar drinks. Neuron, 44(2), 379-387. https://doi.org/10.1016/i.neuron.2004.09.019

Mileti, A., Guido, G., \& Prete, M. I. (2016). Nanomarketing: A new frontier for neuromarketing. Psychology \& Marketing, 33(8), 664-674. https://doi.org/10.1002/mar.20833

Milosavljevic, M., Navalpakkam, V., Koch, C., \& Rangel, A. (2012). Relative visual saliency differences induce sizable bias in consumer choice. Journal of Consumer Psychology, 22(1), 67-74. https://doi.org/10.1016/j.jcps.2011.10.002

Morillo, L. M. S., Alvarez-Garcia, J. A., Gonzalez-Abril, L., \& Ramírez, J. A. O. (2016). Discrete classification technique applied to TV advertisements liking recognition system based on low-cost EEG headsets. Biomedical Engineering Online, 15(1), 197218. https://doi.org/10.1186/s12938-016-0181-2

Murphy, E., Illes, J., \& Reiner, P. (2008). Neuroethics of neuromarketing. Journal of Consumer Behaviour, 7(4), $293-302$. https://doi.org/10.1002/cb.252

Myers, D. G., \& DeWall, N. C. (2021). Psychology (13th ed.). New York, USA. Worth Publishers. 
Nemorin, S., \& Gandy-Jr, O. H. (2017). Exploring neuromarketing and its reliance on remote sensing: Social and ethical concerns. International Journal of Communication, 11, 4824-4844.

Orzan, G., Zara, I., \& Purcarea, V. (2012). Neuromarketing techniques in pharmaceutical drugs advertising: A discussion and agenda for future research. Journal of Medicine and Life, 5(4), 428-432.

Page, G. (2012). Scientific realism: What neuromarketing can and can't tell us about consumers. International Journal of Market Research, 54(2), 287-290. https://doi.org/10.2501/IJMR-54-2-287-290

Papez, J. W. (1937). A proposed mechanism of emotion. Archives of Neurology Psychiatry, 38(4), 725-743. https://doi.org/10.1001/archneurpsyc.1937.02260220069003

Plassmann, H., Ramsoy, T. Z., \& Milosavljevic, M. (2012). Branding the brain: A critical review and outlook. Journal of Consumer Psychology, 22(1), 18-36. https://doi.org/10.1016/i.jcps.2011.11.010

Pozharliev, R., Verbeke, W. J., \& Bagozzi, R. P. (2017). Social consumer neuroscience: Neurophysiological measures of advertising effectiveness in a social context. Journal of Advertising, 46(3), 351-362. https://doi.org/10.1080/00913367.2017.1343162

Ramos, T., Marques, J., \& Garcia-Marques, L. (2017). The memory of what we do not recall: Dissociations and theoretical debates in the study of implicit memory. Psicológica, 38(2), 365-393.

Ramsoy, T. Z. (2015). Introduction to neuromarketing \& consumer neuroscience. Rørvig, Denmark. Neurons Inc.

Ruschendorf, J. (2020). Neuromarketing: Insights into the consumer brain and its adaption to brand management. (Bachelor), Novia University of Applied Sciences, Turku, Finland.

Russell, J. A., \& Barrett, L. F. (1999). Core affect, prototypical emotional episodes, and other things called emotion: Dissecting the elephant. Journal of Personality and Social Psychology, 76(5), 805. https://doi.org/10.1037//0022-3514.76.5.805

Scheff, T. J., Wentworth, W. M., \& Ryan, J. (1995). Social perspectives on emotions. Contemporary Sociology, 24(4), 25-46. https://doi.org/10.2307/2077690

Scherer, K. R. (2005). What are emotions? And how can they be measured? Social Science Information, 44(4), 695-729. https://doi.org/10.1177/0539018405058216

Schiller, D., Freeman, J. B., Mitchell, J. P., Uleman, J. S., \& Phelps, E. A. (2009). A neural mechanism of first impressions. Nature Neuroscience, 12(4), 508-522. https://doi.org/10.1038/nn.2278

Sebastian, V. (2014). Neuromarketing and evaluation of cognitive and emotional responses of consumers to marketing stimuli. Procedia Social Behavioral Sciences, 127(2), 753-757. https://doi.org/10.1016/i.sbspro.2014.03.349

Sirico Jr, L. J. (2017). The Trial Lawyer and the Reptilian Brain: A Critique. Cleveland State Law Review 65(3), $411-425$.

Spence, C. (2020). On the ethics of neuromarketing and sensory marketing. In Organizational Neuroethics (pp. 9-29). Switzerland. Springer. https://doi.org/10.1007/978-3-030-27177-0 3

Spielman, R. M., Dumper, K., Jenkins, W., Lovett, M., \& Perlmutter, M. (2014). Psychology. Houston, USA. OpenStax.

Stanton, S., Armstrong, W., \& Huettel, S. (2017). Neuromarketing: Ethical implications of its use and potential misuse. Journal of Business Ethics, 144(4), 799-811. https://doi.org/10.1007/s10551-016-3059-0

Stewart, P. A., Eubanks, A. D., Dye, R. G., Gong, Z. J. H., Bucy, E. P., Wicks, R. H., \& Eidelman, S. (2018). Candidate Performance and Observable Audience Response: Laughter and Applause-Cheering During the First 2016 Clinton-Trump Presidential Debate. Frontiers in Psychology, 9, 15. https://doi.org/10.3389/fpsyg.2018.01182

Ulman, Y. I., Cakar, T., \& Yildiz, G. (2015). Ethical Issues in neuromarketing: I consume, therefore I am. Science and Engineering Ethics, 21(5), 1271-1284. https://doi.org/10.1007/s11948-014-9581-5

Vecchiato, G., Cherubino, P., Trettel, A., \& Babiloni, F. (2013). Neuroelectrical brain imaging tools for the study of the efficacy of TV advertising stimuli and their application to neuromarketing. Verlag Berlin Heidelberg, Germany. Springer. https://doi.org/10.1007/978-3-642-38064-8

Zaltman, G. (2000). Consumer researchers: Take a hike! Journal of Consumer Research, 26(4), 423-428. https://doi.org/10.1086/209573 